\title{
Capsule Commentary on Pilla et al., Predictors of Insulin Initiation in Patients with Type 2 Diabetes: an Analysis of the Look AHEAD Randomized Trial
}

\author{
Rosette J. Chakkalakal, MD, MHS \\ Vanderbilt University Medical Center, Nashville, TN, USA. \\ J Gen Intern Med 33(6):944 \\ DOI: $10.1007 / \mathrm{s} 11606-018-4358-1$ \\ (c) Society of General Internal Medicine 2018
}

$\mathrm{T}$ his study by Pilla et al. ${ }^{1}$ identifies sociodemographic and clinical predictors of insulin initiation among participants enrolled in the Look AHEAD (Action for Health in Diabetes) trial. $^{2}$ Nearly $28 \%$ of study participants not using insulin at baseline were found to have initiated insulin for management of type 2 diabetes during a median follow-up of 8 years. Using Cox proportional hazards models, the investigators found that insulin initiation was inversely associated with older age and Black or Hispanic race/ethnicity and positively associated with hemoglobin A1C, current smoking, body mass index, hypertension, the presence of macrovascular and microvascular complications, number of antihyperglycemic drugs, family history of diabetes, and care at a hospital-affiliated medical clinic.

The decision to intensify type 2 diabetes treatment, especially via insulin initiation, requires "a patient-centered approach, including assessment of efficacy, hypoglycemia risk, impact on weight, side effects, costs, and patient preferences". ${ }^{3}$ Thus, insulin initiation may be appropriate for some but not all patients. Pilla et al. are unable to explain the extent to which the differences they identified in insulin initiation may be explained by appropriateness of insulin initiation because their analysis did not account for all of the factors included in the decision-making process. In particular, hypoglycemic risk may play a critical role in the decision to initiate insulin given increased recognition of the significant negative impact of hypoglycemia on long-term outcomes of patients with type 2 diabetes ${ }^{4}$ but it was not addressed in this study.
As stated by the authors, the racial/ethnic differences in insulin initiation identified in this study are especially noteworthy and deserve further evaluation. Discerning between differences and disparities in treatment by race/ethnicity requires knowledge of treatment appropriateness, patient attitudes and preferences for the treatment, and clinical outcomes of the treatment across racial/ethnic groups. ${ }^{5}$ Clarifying if the racial/ethnic variation identified in this study represents differences or disparities would greatly inform efforts to ensure equitable treatment of type 2 diabetes for all patients.

Corresponding Author: Rosette J. Chakkalakal, MD, MHS; Vanderbilt University Medical Center, Nashville, TN, USA (e-mail: Rosette.j. chakkalakal@vanderbilt.edu).

\section{Compliance with Ethical Standards:}

Conflict of Interest: The author declares that she does not have a conflict of interest.

\section{REFERENCES}

1. Pilla SJ, Yeh HC, Juraschek SP, Clark JM, Maruthur NM, Predictors of insulin initiation in patients with type 2 diabetes: an analysis of the Look AHEAD randomized trial. J Gen Intern Med. https://doi.org/10.1007/ s11606-017-4282-9

2. Look AHEAD Research Group, Wing RR, Bolin P, et al. Cardiovascular effects of intensive lifestyle intervention in type 2 diabetes. N Engl J Med 2013;369(2): 145-54.

3. American Diabetes Association. 8. Pharmacologic approaches to glycemic treatment: standards of medical care in diabetes-2018. Diabetes Care. 2018;41(Suppl 1):S73-S85.

4. Lipska KJ, Ross JS, Wang Y, et al. National trends in US hospital admissions for hyperglycemia and hypoglycemia among Medicare beneficiaries, 1999 to 2011. JAMA Int Med 2014;174(7):1116-24.

5. Rathore SS, Krumholz HM. Differences, disparities, and biases: clarifying racial variations in health care use. Ann Int Med 2004; $141(8): 635-8$. 